American Journal of Pharmacology and Toxicology 3 (1): 160-167, 2008

ISSN 1557-4962

(C) 2008 Science Publications

\title{
Neuroprotection Afforded by GABA Against Oxygen-Glucose Deprivation-Induced Injury in Rat Cortical Brain Slices: An Hormetic Dose-Response Effect
}

\author{
Lorenzo Ricci, Massimo Valoti, Giampietro Sgaragli and Maria Frosini \\ Dipartimento di Scienze Biomediche, Sezione di Farmacologia, Fisiologia e Tossicologia, \\ Università di Siena, viale A. Moro 2, lotto C, 53100 Siena, Italy
}

\begin{abstract}
The aim of the present investigation was to assess neuroprotection exerted by GABA (100 $\mathrm{nM}-100 \mathrm{mM}$ ) in rat cortical brain slices subjected to oxygen-glucose deprivation and reoxygenation. Neuronal injury and neuroprotection were assessed by measuring the release of glutamate and lactate dehydrogenase and tissue water content. Results demonstrate that GABA exerted neuroprotective effects according to a U-shaped, hormetic-like, concentration-response curve, with an efficacy window of 10-100 $\mu \mathrm{M}$ concentration. In order to verify whether GABA-neuroprotective effects were $\mathrm{GABA}_{\mathrm{A}^{-}}$ or $\mathrm{GABA}_{\mathrm{B}}$-mediated, Muscimol $\left(\mathrm{GABA}_{\mathrm{A}}\right.$ agonist) and Baclofen $\left(\mathrm{GABA}_{\mathrm{B}}\right.$ agonist) were tested. Results demonstrated that only Muscimol exerted neuroprotection according to a U-shaped, hormetic-like, concentration-response curve, while baclofen was ineffective. In conclusion, the hormetic response of GABA or $\mathrm{GABA}_{\mathrm{A}}$ agonists should be taken into consideration when designing experiments aimed at assessing neuroprotection by these agents against ischemia/reoxygenation injury.
\end{abstract}

Key words: Brain ischemia, GABA, hormesis, GABA agonist/antagonist, neuroprotection

\section{INTRODUCTION}

Ischemic injury to cerebral tissues triggers complex biochemical cascades that ultimately lead to neuronal death. Excessive excitatory neurotransmitter release occurs during this process, stimulating excitotoxic conditions that hasten depletion of oxygen and nutrients. Therefore, neuroprotective therapy goals are to antagonize the neuronal damage-promoting mechanisms and to strengthen the auto protective pathways in an attempt to prevent cells at risk from dying $^{[1,2]}$. Gamma-aminobutyric acid (GABA) is the most abundant inhibitory neurotransmitter of human cerebrum. The application of drugs that promote neuronal inhibition mediated by GABA receptor, may be a strategy to prevent neuronal injury. Increasing GABA function might thus represent a beneficial therapeutic approach to acute ischemia for different reasons ${ }^{[3,4,5]}$. First, endogenous GABA synthesis and release are decreased after an ischemic insult with consequent reduction in GABAergic transmission ${ }^{[4]}$. Second, since glutamatergic and GABAergic system work by counterbalancing each the function of the other, the enhancement of GABAergic activity should antagonize the excessive glutamatergic excitation, which is the pivotal event leading to cell death. Thus, an abundance of literature deals with the putative neuroprotective potential of GABAergic compounds ${ }^{[4]}$. Many in vitro and in vivo data demonstrate efficacy in various neuropathological models: however, studies tend to be equivocal and clinical trials have so far been disappointing. Interestingly, a recent study performed in this laboratory, demonstrated that diazepam was neuroprotective in an in vitro model of brain ischemia (rat cortical brain slices subjected to oxygen-glucose deprivation and reoxygenation ${ }^{[6]}$. On the other hand, its neuroprotective effects followed an U-shaped concentration-response curve typical of drugs that exhibit an hormetic-like effect and this could explain the failure of diazepam to protect brain tissues against the damage from ischemia/reoxygenation injury observed in some studies. The aim of the present work was to assess whether the pharmacological conditioning hormesis exhibited by the benzodiazepine receptor agonist diazepam is indeed possessed by GABA itself. This could help in designing experiments aimed at assessing whether such agent (s) may be successfully employed as neuroprotectants against ischemia/reoxygenation injury. Consequently, the degree of neuroprotection afforded by a wide range of GABA concentrations (100 nM-100 mM) in rat cortical brain slices subjected to oxygen-glucose deprivation

Corresponding Author: Maria Frosini, Dipartimento di Scienze Biomediche, Università di Siena, Sezione di Farmacologia, Fisiologia e Tossicologia, Polo Scientifico di San Miniato, Via A. De Gasperi, 2, 53100 Siena, Italy Tel: +390577234441 (Office); +390577234435 (Lab) Fax: +39057723446 
(OGD) and reperfusion was studied. Tissue damage and protection were assessed by measuring the release of glutamate (GLU) and lactate dehydrogenase (LDH) into bathing artificial cerebrospinal fluid (ACSF) during reperfusion and by determining tissue edema at the end of the experiment.

\section{MATERIALS AND METHODS}

Animals and slices preparation: All experiments were performed in strict compliance with the recommendation of the EEC (86/609/CEE) for the care and use of laboratory animals and the protocols were approved by the Animal Care and Ethics Committee of the University of Siena, Italy. Male Sprague-Dawley rats (7-10 weeks, 350-450 g; Charles River Italia, Calco, Italy) were sacrificed and the whole brain rapidly removed and placed in cold oxygenated ACSF (composition in mM: $120 \mathrm{NaCl}, 2.5 \mathrm{KCl}, 1.3 \mathrm{MgCl}_{2}$, 1.0 $\mathrm{NaH}_{2} \mathrm{PO}_{4}, 1.5 \mathrm{CaCl}_{2}, 26 \mathrm{NaHCO}_{3}, 11$ glucose, saturated with $95 \% \mathrm{O}_{2}-5 \% \mathrm{CO}_{2}$, with a final $\mathrm{pH}$ of 7.4 , osmolality 285-290 mOsmol). The cortex was dissected and cut into $400 \mu \mathrm{m}$-thickness coronal slices by using a manual chopper (Stoelting Co., Wood Dale, IL, USA). Afterward, slices were maintained in oxygenated ACSF enriched with $400 \mu \mathrm{M}$ ascorbic acid for $1 \mathrm{~h}$ at room temperature to allow maximal recovery from slicing trauma $^{[7]}$.

In vitro ischemia-like conditions: Cortical slices (4-5, total wet weight $33.6 \pm 2.6 \mathrm{mg}, \mathrm{n}=10$ ) were then placed in covered incubation flasks, containing $2 \mathrm{ml}$ ACSF continuously bubbled with $95 \% \quad \mathrm{O}_{2} / 5 \% \quad \mathrm{CO}_{2}$ and incubated at $37^{\circ} \mathrm{C}$ for an additional period of $30 \mathrm{~min}$. Afterwards, OGD was carried out by incubating slices for $30 \mathrm{~min}$ (or for $5,15,30$ or $60 \mathrm{~min}$ in the timedependent induced injury experiments, see below) into ACSF in which glucose had been replaced by an equimolar amount of saccharose and continuously bubbled with $95 \% \mathrm{~N}_{2} / 5 \% \mathrm{CO}_{2}$. After the OGD period, this solution was replaced by fresh, oxygenated ACSF for an additional $90 \mathrm{~min}$ period (reoxygenation). In drug-treated slices, OGD was followed by reoxygenation with ACSF containing GABA, muscimol, or baclofen.

Assessment of neuronal injury: Neuronal damage was assessed quantitatively by measuring the amount of both glutamate and LDH released into the ACSF during 90 min-reoxygenation period. In particular, glutamate concentration was determined fluorimetrically (excitation $340 \mathrm{~nm}$; emission: $460 \mathrm{~nm}$ ) using the conversion of $\mathrm{NAD}^{+}$to $\mathrm{NADH}$ by glutamate dehydrogenase ${ }^{[8]}$ while LDH activity was determined spectrophotometrically by the rate of decrease in absorbance at $340 \mathrm{~nm}$ via the oxidation of NADH to $\mathrm{NAD}^{+[9]}$. Tissue water gain (edema) was calculated as (wet weight - dry weight)(dry weight) $)^{-1}$ and given as $g$ $\mathrm{H}_{2} \mathrm{O}\left(\mathrm{g} \mathrm{dw}^{-1}\right.$ as described by MacGregor et al. ${ }^{[10]}$.

Data Analysis: All the experiments were performed by using brain slices derived from at least 4 different rats. Data are reported as mean \pm S.E.M. and $n$ is defined as the number of cluster of slices. For glutamate and LDH activity, data are expressed as nmol mg ${ }^{-1}$ wet tissue and $\mathrm{U} \mathrm{mg}^{-1}$ wet tissue, respectively. One unit (U) of LDH activity is defined as that which gives rise to the formation of one micromole of lactate in one minute.

Statistical analysis was performed by using oneway ANOVA followed by post-hoc Dunnett test (GraphPad INSTAT v3.00, GraphPad Software, San Diego, CA, USA).

\section{RESULTS AND DISCUSSION}

Effects of different time periods of OGD/reperfusion on glutamate- and LDH- release and tissue edema in rat cortical slices: In order to establish the time period of OGD that induced maximal damage to the brain tissue, cortical slices were subjected to $5,15,30$ or 60 min of OGD followed by $90 \mathrm{~min}$ of reperfusion. Rat cortical slices incubated in ACSF for 120 min (control conditions, CTRL) released into the medium $0.31 \pm 0.02$ nmol mg tissue $(\mathrm{n}=8)$ and $4.1 \pm 0.6 \mathrm{U} \mathrm{mg}^{-1}$ prot. $(n=17)$ of GLU and LDH, respectively. After 120 min incubation in ACSF, water gain of CTRL slices was $9.93 \pm 0.4 \mathrm{~g} \mathrm{H}_{2} \mathrm{O}$ ( $\mathrm{g}$ dry weight $)^{-1}(\mathrm{n}=16)$ : this value was about $4.0 \%$ higher than that measured after $1 \mathrm{~h}$ recovery period at room temperature ${ }^{[10]}$. As shown in Fig. 1, the release of glutamate and $\mathrm{LDH}$, as well as water gain, increased linearly with the duration of OGD. When ischemia-like conditions were limited to 5 min, statistically significant changes were observed only for glutamate and $\mathrm{LDH}$ release $(+53$ and $+138 \%$ versus CTRL, respectively) while tissue edema was not modified. On the contrary, 15, 30 and $60 \mathrm{~min}$ of OGD followed by $90 \mathrm{~min}$ of reoxygenation caused a more pronounced neuronal injury. In particular, the highest glutamate- and LDH-release were observed at $30 \mathrm{~min}$ $(+107 \%$ and $+340 \%$ versus control values, respectively) which were accompanied by a huge edema (+142\% versus control). However, when the duration of OGD was increased up to $60 \mathrm{~min}$, the amount of glutamate and LDH released into ACSF as well as tissue water gain were very close to those observed after $30 \mathrm{~min}$. Therefore, in all subsequent experiments, OGD of cortical slices was limited to $30 \mathrm{~min}$. 
Am. J. Pharm. \& Toxicol., 3 (1): 160-167, 2008

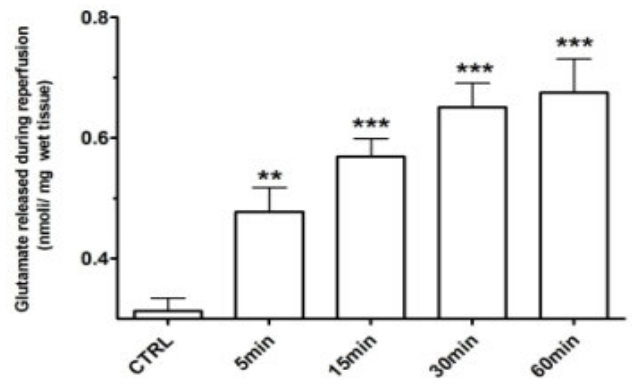

(A)

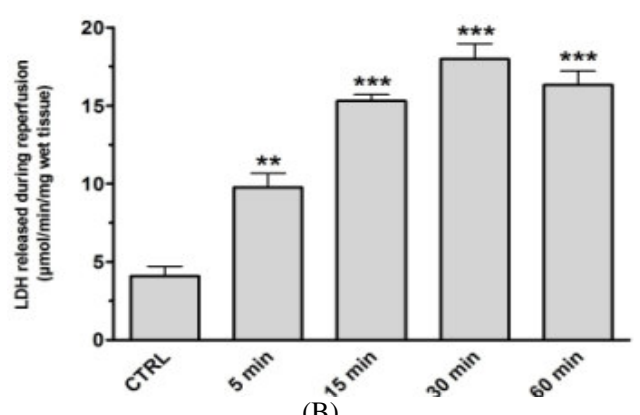

(B)

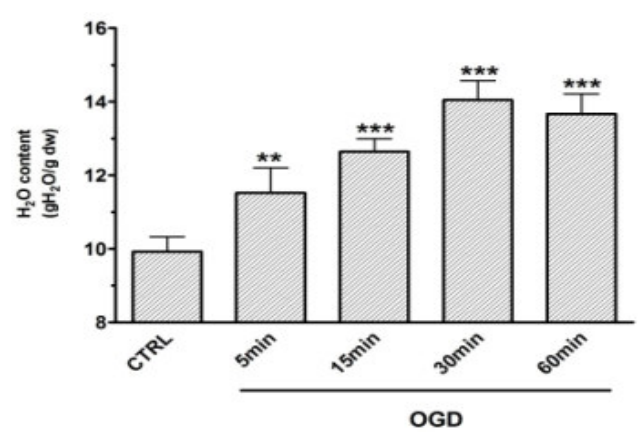

(C)

Fig. 1: Effects of different time periods of OGD and reperfusion on glutamate- and LDH- release and tissue edema. Rat cortical slices were incubated in artificial cerebrospinal fluid for $120 \mathrm{~min}$ (control conditions, CTRL) or exposed to 5, 15, 30 and $60 \mathrm{~min}$ of OGD followed by $90 \mathrm{~min}$ of reoxygenation. OGD/reoxygenation-induced release of glutamate, $\mathrm{LDH}$ and tissue water content are reported in panel A, B and C respectively. Data are means \pm S.E.M. of 4 different experiments. Statistical analysis was performed by using ANOVA followed by posthoc Dunnett test. $* * \mathrm{p}<0.01, * * * \mathrm{p}<0.001$ vs CTRL

Effect of GABA on OGD and reperfusion-induced glutamate and $\mathrm{LDH}$ release and tissue edema in rat cortical slices: As shown in Fig. 2 (panels A and B),

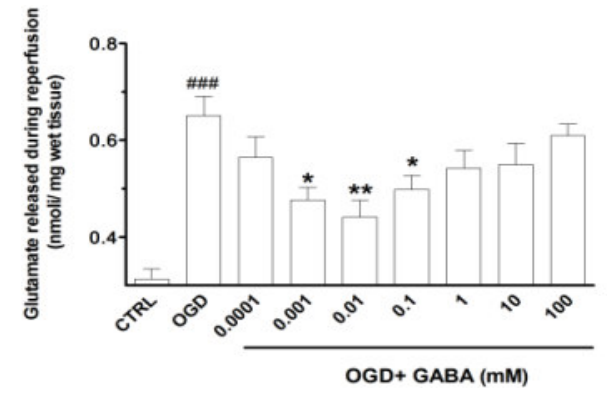

(A)

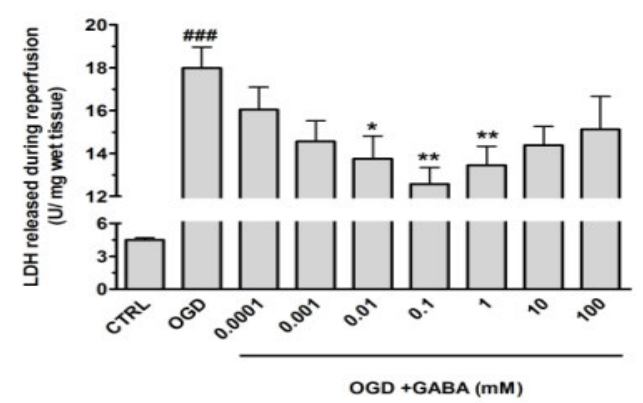

(B)

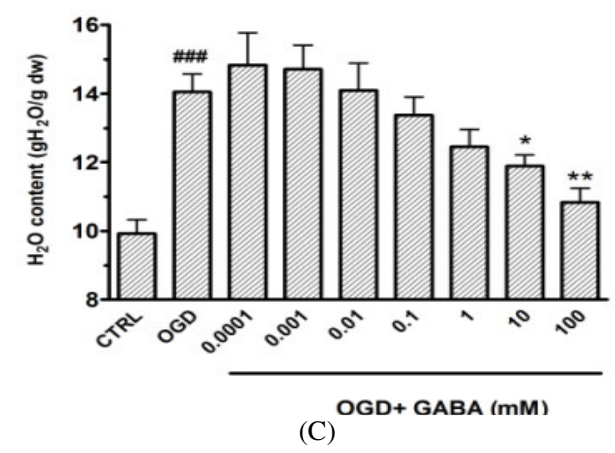

Fig. 2: Effect of GABA on OGD and reperfusion induced release of glutamate (panel A), LDH (panel B) and tissue edema (panel C) in rat cortical slices. Slices were incubated in artificial cerebrospinal fluid for $120 \mathrm{~min}$ (control conditions, CTRL) or exposed to 30 min of OGD followed by $90 \mathrm{~min}$ of reoxygenation (OGD). GABA (100 Nm-100 $\mathrm{mM}$ ) was added during reoxygenation phase. Data are means \pm S.E.M. of 5 different experiments. Statistical analysis was performed by using ANOVA followed by post-hoc Dunnett test. ${ }^{*} \mathrm{p}<0.05, * * \mathrm{p}<0.01$, vs OGD, ${ }^{\# \# \#}$ $\mathrm{p}<0.001$ vs CTRL

GABA (100 nM-100 mM) significantly reduced oxygen/glucose deprivation- and reoxygenationinduced glutamate and LDH release. These effects, 
however, followed a U-shaped concentration-response curve, typical of a chemical postexposure conditioning hormesis effect ${ }^{[11]}$. In particular, in the range of concentrations between $1 \mu \mathrm{M}$ and $1 \mathrm{mM}$, GABA significantly antagonised glutamate and LDH release, while at lower $(10 \mathrm{nM}-1 \mu \mathrm{M})$ or higher $(10-100 \mathrm{mM})$ concentrations it did not reduce significantly both parameters. The most effective GABA concentrations turned out to be 10 and $100 \mu \mathrm{M}$ which were capable to decrease the release of glutamate to $0.44 \pm 0.03$ $\mathrm{nmol} / \mathrm{mg}$ tissue $(\mathrm{p}<0.01, \mathrm{n}=9)$ and that of $\mathrm{LDH}$ to $12.6 \pm 0.7 \mathrm{U} \mathrm{mg}^{-1}$ proteins $(\mathrm{p}<0.01, \mathrm{n}=11-16)$, respectively. GABA significantly antagonised tissue water gain in a concentration-dependent fashion being 10 and $100 \mathrm{mM}$ the most effective concentrations. Oxygen/glucose deprivation- and reoxygenationinduced water gain, in fact, was reduced by $50 \%$ $(\mathrm{p}<0.05, \mathrm{n}=20)$ and by $78.8 \%(\mathrm{p}<0.01, \mathrm{n}=10)$, respectively (Fig. 2, panel C).

Effect of Muscimol and Baclofen on OGD and reperfusion-induced glutamate and $L D H$ release and tissue edema in rat cortical slices: To verify whether $\mathrm{GABA}$ effects where $\mathrm{GABA}_{\mathrm{A}}$-or $\mathrm{GABA}_{\mathrm{B}}$ mediated, the $\mathrm{GABA}_{\mathrm{A}}$ receptor agonist muscimol and the $\mathrm{GABA}_{\mathrm{B}}$ receptor agonist baclofen were used. Both agonists by themselves, as well as GABA, did not modify glutamate and LDH release and tissue edema in control conditions (data not shown). Interestingly, muscimol (1 $\mathrm{nM}-100 \mu \mathrm{M})$ reduced OGD-induced glutamate and LDH release, as well as tissue edema (Fig. 3). These effects, as already shown for GABA, followed an U-shaped concentration-response curve, typical of an hormetic behaviour. In particular, muscimol in the range of $10 \mathrm{nM}-1 \mu \mathrm{M}$ concentrations, significantly reduced OGD/reperfusion-induced release of GLU, while lower $(1 \mathrm{nM})$ or higher $(10-100 \mu \mathrm{M})$ concentrations were ineffective (Fig. 3, panel A). At 10 $\mathrm{nM}$ and $100 \mathrm{nM}$ concentrations, muscimol reduced glutamate release to $0.45 \pm 0.03 \mathrm{nmol} \mathrm{mg} \mathrm{m}^{-1}$ tissue $(\mathrm{p}<0.01, \mathrm{n}=10)$ and $0.40 \pm 0.03 \mathrm{nmol} \mathrm{mg}^{-1}$ tissue $(\mathrm{p}<0.01, \mathrm{n}=19)$, respectively. Similarly, also LDH release was reduced to $13.4 \pm 0.7 \mathrm{U} \mathrm{mg}^{-1}$ prot $(\mathrm{p}<0.01, \mathrm{n}$ $=18)$ and $14.3 \pm 0.8 \mathrm{U} \mathrm{mg}^{-1}$ prot $(\mathrm{p}<0.05, \mathrm{n}=16)$, by $100 \mathrm{nM}$ and $1000 \mathrm{nM}$ muscimol, respectively (Fig. 3, panel B). In addition, muscimol significantly reduced tissue water gain induced by OGD/reperfusion (Fig. 3, panel C). Edema was reduced to $11.7 \pm 0.3 \mathrm{~g} \mathrm{H}_{2} \mathrm{O} \mathrm{g}^{-1}$ dry weight $(\mathrm{p}<0.05, \mathrm{n}=10)$ by $10 \mu \mathrm{M}$ muscimol while lower $(1 \quad n M-1 \mu \mathrm{M})$ or higher $(50-100 \mu \mathrm{M})$ concentrations did not significantly affect tissue edema.

Baclofen was added to the reoxygenation buffer in a concentration range between 0.1 and $100 \mu \mathrm{M}$. The $\mathrm{GABA}_{\mathrm{B}}$ agonist, however, was not effective in reducing

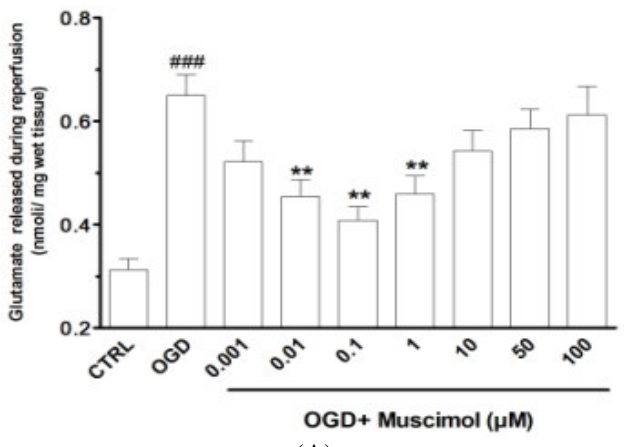

(A)

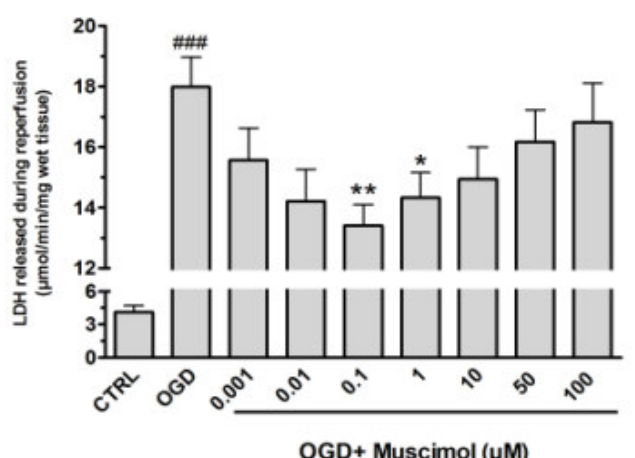

(B)

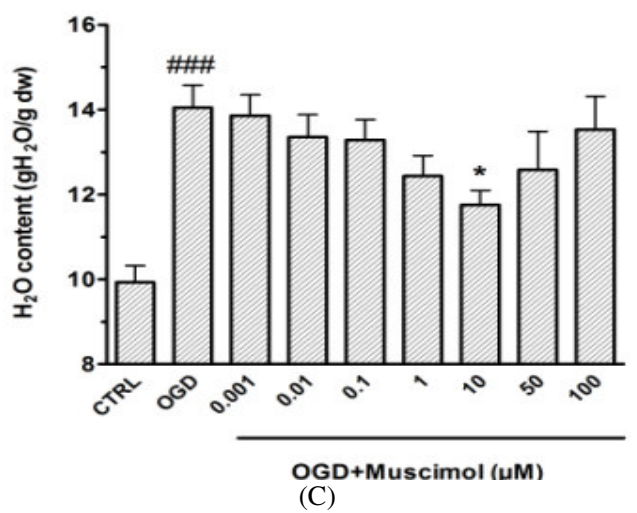

Fig. 3: Effect of Muscimol on OGD and reperfusioninduced release of glutamate (panel A), LDH (panel B) and tissue edema (panel C) in rat cortical slices. Slices were incubated in artificial cerebrospinal fluid for $120 \mathrm{~min}$ (control conditions, CTRL) or exposed to $30 \mathrm{~min}$ of OGD followed by $90 \mathrm{~min}$ of reoxygenation (OGD). Muscimol (1 Nm-100 $\mu \mathrm{M}$ ) was added during the reoxygenation phase. Data are means \pm S.E.M. of 5 different experiments. Statistical analysis was performed by using ANOVA followed by post-hoc Dunnett test. $* \mathrm{p}<0.05, * * \mathrm{p}<0.01$, vs OGD, \#\# $\mathrm{p}<0.001$ vs CTRL 


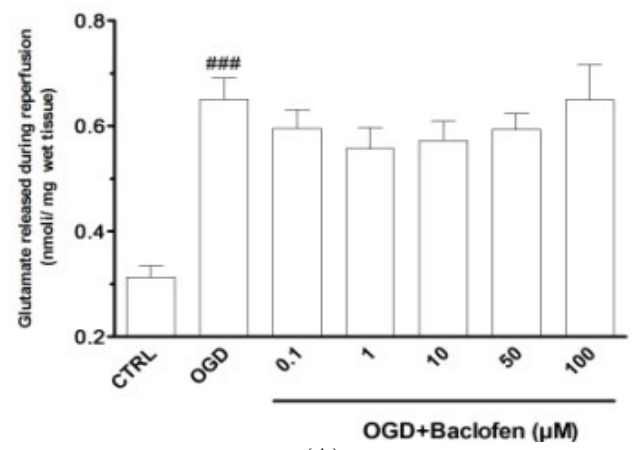

(A)

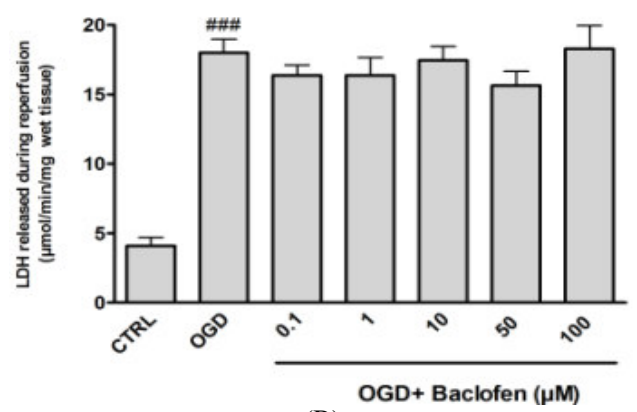

(B)

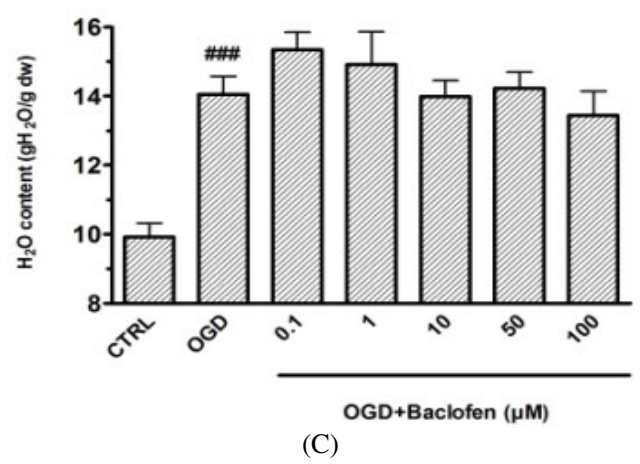

Fig. 4: Effect of Baclofen on OGD and reperfusioninduced release of glutamate (panel A), LDH (panel B) and tissue edema (panel C) in rat cortical slices. Slices were incubated in artificial cerebrospinal fluid for $120 \mathrm{~min}$ (control conditions, CTRL) or exposed to $30 \mathrm{~min}$ of OGD followed by $90 \mathrm{~min}$ of reoxygenation (OGD). Baclofen $(0.1 \mu \mathrm{M}-100 \mu \mathrm{M})$ was added during the reoxygenation phase. Data are means \pm S.E.M. of 4 different experiments. Statistical analysis was performed by using ANOVA followed by post-hoc Dunnett test. $\mathrm{p}<0.001$ vs CTRL

OGD and reperfusion-induced glutamate and LDH release and tissue water gain (Fig. 4).
Since some studies have reported that coactivation of $\mathrm{GABA}_{\mathrm{A}}$ and $\mathrm{GABA}_{\mathrm{B}}$ receptor is required for neuroprotection when counteracting in vitro ischemialike conditions ${ }^{[12]}$ we added $1 \mu \mathrm{M}$ baclofen to a neuroprotective $(0.1 \mu \mathrm{M})$ or an ineffective $(10 \mu \mathrm{M})$ muscimol concentration (Fig. 5). Both drugs were added to the ACSF used during reoxygenation period. Results demonstrated that the addition of baclofen did not modify the effects elicited by muscimol alone.

The data in the present study provide further support to the hypothesis that, by increasing GABAergic transmission, it is possible to counteract the neuronal death subsequent to an ischemic insult ${ }^{[3,4,5]}$. However, it was also found that GABA-mediated neuroprotection during energy deprivation was essentially mediated by $\mathrm{GABA}_{\mathrm{A}^{-}}$, while $\mathrm{GABA}_{\mathrm{B}}$ receptors were not involved.

In the presence of exogenous GABA, neuroprotective effects similar to those obtained with muscimol were observed. GABA may exert neuroprotection not only by directly inhibiting neurons ${ }^{[4]}$, but also by exerting an inhibitory influence on glutamate-mediated neuronal activity ${ }^{[13]}$. Consequently, it is conceivable that the neuroprotection (in terms of reduced glutamate-and LDH-release as well as cell swelling) observed after GABA and muscimol treatment could depend on a reduction in glutamate-induced neurotoxicity. In agreement with this hypothesis, it has been shown that GABA and muscimol prevent NMDA-, AMPA-, or kainateinduced neuronal death in mouse cortical cell cultures $^{[14,15]}$. In the present study, however, the effect of both GABA and muscimol were not concentrationdependent, but resembled a chemical postexposure conditioning hormetic effect ${ }^{[11]}$. This hormetic trend might be explained by different mechanisms. Cerebral ischemia is accompanied by disruption of neuronal ionic homeostasis, including significant increases in intracellular $\mathrm{Na}^{+}, \mathrm{Cl}^{-}$and $\mathrm{Ca}^{2+}$, as well as increases in extracellular $\mathrm{K}^{+}$(for a review, see reference 4). Previous studies indicate that during oxygen-glucose deprivation in rat hippocampal neurons intracellular $\mathrm{Cl}^{-}$ concentrations rise probably because of an enhanced activity of the $\mathrm{Cl}^{-}$cotransporter NKCC- $1^{[16,17]}$. Reoxygenation causes intracellular $\mathrm{Cl}^{-}$to recover, but is followed by a second prolonged rise in intracellular $\mathrm{Cl}^{-[17]}$. It is conceivable that an elevated increase in GABA and muscimol levels at synaptic cleft during reoxygenation might cause an excessive activation of $\mathrm{GABA}_{\mathrm{A}}$ receptors, which aggravates the overload of $\mathrm{Cl}^{-}$in neurons ${ }^{[15]}$ as suggested by the present study where high concentrations of these drugs were used. The major consequence of the excessive rise in 


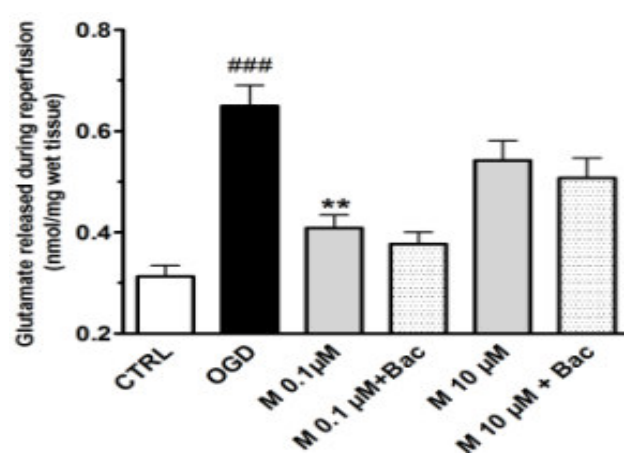

(A)

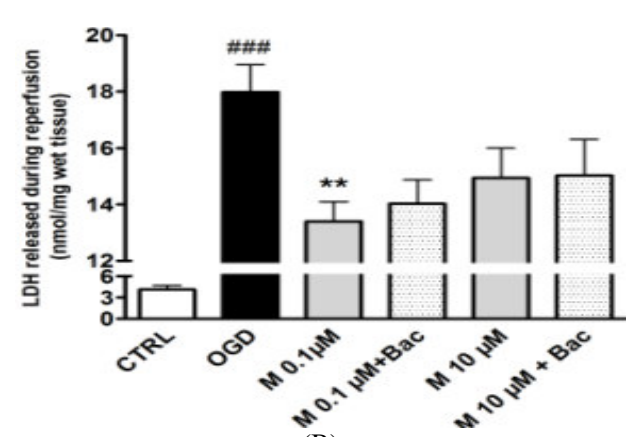

(B)

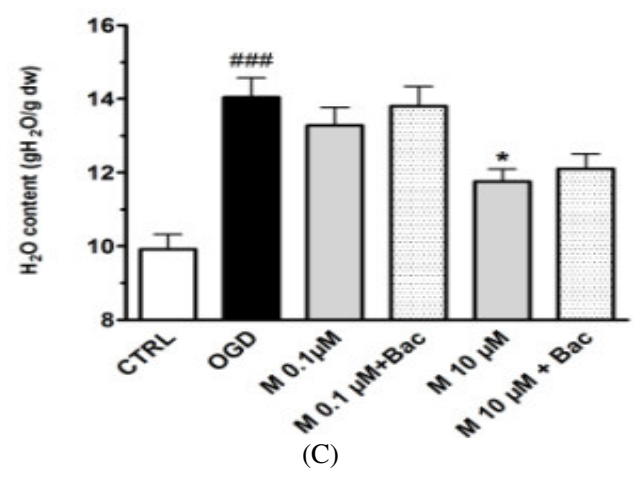

Fig. 5: Effects of muscimol (M) or muscimol+baclofen $(\mathrm{M}+\mathrm{Bac})$ on OGD/reoxygenation-induced release of glutamate (Panel A), LDH (Panel B) and tissue edema (Panel C) in rat cortical slices. Drugs were added to the reoxygenation buffer after $30 \mathrm{~min}$ of OGD at the following concentrations: Muscimol $0.1 \mu \mathrm{M}$ or $10 \mu \mathrm{M}$, Baclofen, $1 \mu \mathrm{M}$. Data are means \pm S.E.M. of 4 different experiments. Statistical analysis was performed by using ANOVA followed by posthoc Dunnett test. ${ }^{*} \mathrm{p}<0.05, * * \mathrm{p}<0.01$, vs OGD, \#\#\# $\mathrm{p}<0.001$ vs CTRL

intracellular $\mathrm{Cl}^{-}$is that the normal hyperpolarizing $\mathrm{GABA}_{\mathrm{A}}$ responses become depolarizing ${ }^{[18]}$, thus contributing to neuronal hyperexcitability and damage $^{[19]}$. Furthermore, even under conditions when equilibrium potential for $\mathrm{Cl}^{-}$does become more positive relative to the resting membrane potential, $\mathrm{GABA}_{\mathrm{A}^{-}}$ linked chloride channels mediates a shunting inhibition that suppresses excitation ${ }^{[20]}$. We can speculate that in the case of elevated GABA and muscimol concentrations, this type of inhibition could not operate, thus further leading to neuronal damage. Finally, at the basis of the hormetic GABA- or muscimol-mediated effect may be the excessive activation of $\mathrm{GABA}_{\mathrm{A}}$ receptors, which could provoke a desensitisation of the same receptors, thus causing depolarisation and damage to neurons ${ }^{[15]}$.

While there is convincing evidence that $\mathrm{GABA}_{\mathrm{A}^{-}}$ mimetic drugs are neuroprotective in several animal models of cerebral ischemia ${ }^{[4]}$, less clear is the protective role played by $\mathrm{GABA}_{\mathrm{B}}$ receptors. In the CNS, these receptors are localized on both pre- and post-synaptic neurons and their activation increases $\mathrm{K}^{+}$ channel conductance resulting in hyperpolarization of the neuronal membrane directly or, post-synaptically, through an intervening GTP-binding protein, which inhibits adenylyl cyclase. In presynaptic neurons, $\mathrm{GABA}_{B}$ receptors partly regulate the dynamics of cytosolic $\mathrm{Ca}^{2+}$ and the release of many neurotransmitters ${ }^{[21]}$.

The results of the present study clearly demonstrated that the activation of $\mathrm{GABA}_{\mathrm{B}}$ receptors by baclofen, did not result in neuroprotection. These data are in agreement with those already reported in the literature ${ }^{[15,22,23,24]}$, although some authors reported a neuroprotective role of this $\mathrm{GABA}_{B}$ agonist ${ }^{[25,26]}$. The reason for this discrepancy is still debated and may depend on differences in severity of challenges associated with each experimental model. Furthermore, any neuroprotective effect of baclofen most likely involves inhibition of pre-synaptic release of glutamate, as excessive levels of glutamate and glutamatergic activity have been reported to occur in the most vulnerable regions of the brain following global ischemia $^{[2]}$. The present results, however, demonstrated that baclofen did not modify glutamate release. Consequently, the lack of neuroprotection in terms of LDH release and tissue edema could arise from the failure of baclofen, to reduce ischemia-induced glutamate release. Finally, to further explore the potential role of coactivation of $\mathrm{GABA}_{\mathrm{A}}$ and $\mathrm{GABA}_{\mathrm{B}}$ receptors in GABA-mediated protection, cortical slices were treated simultaneously with muscimol and baclofen. Results demonstrated that the addition of baclofen did not modify muscimol neuroprotective effects, further confirming no involvement of $\mathrm{GABA}_{B}$ receptors in GABA neuroprotection in this brain ischemia/reperfusion experimental model. 
In conclusion, the hormetic-like dose-response curve of GABA as well as that of many GABA mimetics such as muscimol (present study), diazepam ${ }^{[6]}$ and GABA-transaminase inhibitors ${ }^{[12,27]}$ should be taken into consideration when designing experiments aimed at assessing whether such agent(s) may be successfully employed as neuroprotectants against ischemia/reoxygenation injury.

\section{ACKNOWLEDGEMENT}

This study was financed by PAR and MURST funds. The authors are grateful to Severina Mitushewa for her technical assistance.

\section{REFERENCES}

1. Leker, R.R. and M.Y. Neufeld, 2003. Antiepileptic drugs as possible neuroprotectants in cerebral ischemia. Brain Res. Rev., 42: 187-203.

2. Mehta, S.L, N. Manhas and R. Raghubir, 2007. Molecular targets in cerebral ischemia for developing novel therapeutics. Brain Res. Rev., 54: 34-66.

3. Green, A.R, A.H. Hainsworth and D.M. Jackson, 2000. GABA potentiation: A logical pharmacological approach for the treatment of acute ischaemic stroke. Neuropharmacology, 39: 1483-1494.

4. Schwartz-Bloom, R.D. and R. Sah, 2001. GammaAminobutyric acid (A) neurotransmission and cerebral ischemia. J. Neurochem., 77: 353-371.

5. Calabresi, P., L.M. Cupini, D. Centonze, F. Pisani and G. Bernardi, 2003. Antiepileptic drugs as a possible neuroprotective strategy in brain ischemia. Ann. Neurol., 53: 693-702.

6. Ricci, L., M. Valoti , G. Sgaragli and M. Frosini, 2007. Neuroprotection afforded by diazepam against oxygen/glucose deprivation-induced injury in rat cortical brain slices. Eur. J. Pharmacol., 561: 80-84.

7. Brahma, B., R.E. Forman, E.E. Stewart, C. Nicholson and M.E. Rice, 2000. Ascorbate inhibits edema in brain slices. J. Neurochem., 74: 1263-1270.

8. Eilers, H., C.H. Kindler and P.E. Bickler, 1999. Different effects of volatile anesthetics and polyhalogenated alkanes on depolarization-evoked glutamate release in rat cortical brain slices. Anesthesia and Analgesia, 88: 1168-1174.

9. Gay, R.J., R.B. McComb and G.N. Bowers Jr., 1968. Optimum reaction conditions for human lactate dehydrogenase isoenzymes as they affect total lactate dehydrogenase activity. Clin. Chem., 14: 740-753.
10. MacGregor, D.G., M.V. Avshalumov and M.E. Rice, 2003. Brain edema induced by in vitro ischemia: Causal factors and neuroprotection. J. Neurochem., 85: 1402-1411.

11. Calabrese, J.E., K.A. Bachmann and A.J. Bailer et al., 2007. Biological stress response terminology: Integrating the concepts of adaptive response and preconditioning stress within a hormetic dose-response framework. Toxicol. Applied Pharmacol., 222: 122-128.

12. Costa, C., G. Leone, E. Saulle, F. Pisani, G. Bernardi and P. Calabresi, 2004. Coactivation of $\mathrm{GABA}(\mathrm{A})$ and $\mathrm{GABA}(\mathrm{B})$ receptor results in neuroprotection during in vitro ischemia. Stroke, 35: 596-600.

13. Moulder, K.L., J.P. Meeks and S. Mennerick, 2006. Homeostatic regulation of glutamate release in response to depolarization. Molecular Neurobiol., 33: 133-153.

14. Ohkuma, S., S.H. Chen, M. Katsura, D.Z. Chen and K. Kuriyama, 1994. Muscimol prevents neuronal injury induced by NMDA. Jap. J. Pharmacol., 64: 125-128.

15. Muir, J.K., D. Lobner, H. Monyer and D.W. Choi, 1996. GABA $_{A}$ receptor activation attenuates excitotoxicity but exacerbates oxygen-glucose deprivation-induced neuronal injury in vitro. J. Cerebral Blood Flow Metab., 16: 1211-1218.

16. Galeffi, F., R. Sah, B.B. Pond, A. George and R.D. Schwartz-Bloom, 2004. Changes in intracellular chloride after oxygen-glucose deprivation of the adult hippocampal slice: Effect of diazepam. J. Neurosci., 24: 4478-4488.

17. Pond, B.B., K. Berglund, T. Kuner, G. Feng, G.J. Augustine and R.D. Schwartz-Bloom, 2006. The chloride transporter $\mathrm{Na}(+)-\mathrm{K}(+)-\mathrm{Cl}$ - cotransporter isoform-1 contributes to intracellular chloride increases after in vitro ischemia. J. Neurosci., 26: 1396-1406.

18. Thompson, S.M. and B.H. Gahwiler, 1989. Activity-dependent disinhibition. II. Effects of extracellular potassium, furosemide and membrane potential on $\mathrm{ECl}^{-}$in hippocampal CA3 neurons. J. Neurophysiol., 61: 512-523.

19. Allen, N.J., D.J. Rossi and D. Attwell, 2004. Sequential release of GABA by exocytosis and reversed uptake leads to neuronal swelling in simulated ischemia of hippocampal slices. J. Neurosci., 24: 3837-3849.

20. Staley, K.J. and I. Mody, 1992. Shunting of excitatory input to dentate gyrus granule cells by a depolarizing $\mathrm{GABA}_{\mathrm{A}}$ receptor-mediated postsynaptic conductance. J. Neurophysiol., 68: 197-212. 
21. Bettler, B. and J.Y. Tiao, 2006. Molecular diversity, trafficking and subcellular localization of GABAB receptors. Pharmacol. Ther., 110: 533-543.

22. Ito, H., Y. Watanabe, A. Isshiki and H. Uchino, 1994. Neuroprotective properties of propofol and midazolam, but not pentobarbital, on neuronal damage induced by forebrain ischemia, based on the GABAA receptors. Acta Anaesthesiol. Scandinavica, 43: 153-162.

23. Araki, T., H. Kato and K. Kogure, 1991. Comparative protective effects of vinconate, baclofen and pentobarbital against neuronal damage following repeated brief cerebral ischemia in the gerbil brain. Res. Exp. Med., 191: 371-378.

24. Rosenbaum, D.M., J.C. Grotta, L.C. Pettigrew, P. Ostrow, R. Strong, H. Rhoades, C.M. Picone and A.T. Grotta, 1990. Baclofen does not protect against cerebral ischemia in rats. Stroke, 21: 138-140.

25. Cozzi, A., E. Meli, V. Carlà, R. Pellicciari, F. Moroni and D.E. Pellegrini-Giampietro, 2002. Metabotropic glutamate 1 (mGlu1) receptor antagonists enhance GAB Aergic neurotransmission: A mechanism for the attenuation of post-ischemic injury and epileptiform activity? Neuropharmacology, 43: 119-130.
26. Babcock, A.M., A. Everingham, C.M. Paden and M. Kimura, 2002. Baclofen is neuroprotective and prevents loss of calcium/calmodulin-dependent protein kinase II immunoreactivity in the ischemic gerbil hippocampus. J. Neurosci. Res., 67: 804-811.

27. Frosini, M., L. Ricci, M. Valoti, N. Gaggelli and G. Sgaragli, 2005. Neuroprotection afforded by novel gamma- aminobutyric acid aminotransferase inhibitors on rabbit hippocampal and cortex slices exposed to oxygen-glucose deprivation. National Congress of the Italian Society for Neuroscience and Joint Italian-Swedish Neuroscience Meeting, Ischia (Naples, Italy) 1-4 October. Abstract Book, pp: 231. 